\title{
Serum creatine kinase levels in pubertal, mature, pregnant, and postmenopausal women
}

\author{
SARAH BUNDEY, J. M. CRAWLEY, J. H. EDWARDS, AND \\ R. A. WESTHEAD \\ From the Departments of Clinical Genetics and Pathology, Birmingham Maternity Hospital, Birmingham; \\ and the Biochemistry Department, Midland Centre for Neurosurgery and Neurology, \\ Smethwick, Warley, West Midlands
}

SUMMARY In order to obtain control values for the diagnosis of carriers of Duchenne muscular dystrophy, creatine kinase (CK) estimations were performed in two laboratories on 148 healthy teenage girls (of whom 38 were premenarchal and 110 postmenarchal), 133 healthy mature women, 124 pregnant women, and 37 postmenopausal women. These levels were highest in the premenarchal teenagers, and became successively lower in the postmenarchal teenagers, the mature women, and the pregnant women, so that the mean level of the pregnant women was less than half that of the teenagers. The CK levels then rose again after the menopause. If the distribution of CK levels in adult non-pregnant women had been taken as controls for teenagers who were possible carriers for Duchenne muscular dystrophy, then one third of those teenagers classified as carriers would have been so classified incorrectly.

Levels of serum creatine kinase (CK) are used in the distinction of carriers of X-linked muscular dystrophies. Therefore, as part of a genetic study of Duchenne muscular dystrophy in the West Midlands, CK levels in healthy females were studied. Four groups of controls were investigated: teenage girls (subsequently divided into those who were pre- or postmenarchal); healthy non-pregnant women aged between 20 and 40 years; women who were in the first 16 weeks of pregnancy; and postmenopausal women. We chose these groups in view of the need to define control distributions, including youth, pregnancy, and those ages representative of grandmothers whose status are often of value in defining the time of mutation.

The blood was studied on the understanding with the clinicians involved, the girls who gave it, and their parents who allowed it, that under no circumstances would any results be made available. All our records of identity have now been destroyed. It is very unlikely that any carrier would be found in a few hundred women, since the incidence of carriers cannot exceed twice the incidence of disease in males, which is about 1 in 4000 in the West Midlands.

\section{Material and methods}

The teenage controls were 148 girl volunteers from a

Received for publication 9 August 1978 nearby day school. They were bled during the lunch hour having refrained from games on the morning of the test. They had also been asked not to give blood if they had had a minor illness, accident, or unusual exertion in the previous two days. Each girl was asked whether her periods had started and, if so, whether she was menstruating that day.

The 133 healthy non-pregnant females consisted of 124 nurses at the Birmingham Maternity Hospital, who were being tested for rubella antibodies, and 9 graduate and secretarial volunteers from the Infant Development Unit, who were bled during a normal working day. The combined group of adult women aged 20 to 40 years will henceforward be termed 'nurses'. Blood was made available from that taken on booking from 124 pregnant women whose gestation was 16 weeks or less. The blood from women aged over 55 was acquired through the assistance of the Blood Transfusion Centre. About $5 \mathrm{ml}$ blood from donors who were born in 1923 or earlier were put into separate tubes and the serum taken off when the session ended.

The sera from all the controls were thus separated on the day of taking. They were split into two so that CK estimations could be carried out in two laboratories: the Midland Centre for Neurosurgery and Neurology (MCNN) and the Queen Elizabeth Medical Centre (QEMC). Estimations on sera from the nurses and pregnant women were performed on 117 
the same specimens within two days; until then the sera was stored at $4^{\circ} \mathrm{C}$. These women were not known to be controls by the biochemists who tested the samples. Sera from the teenage girls and from the elderly blood donors were frozen once, and the estimations were performed in a group.

The method of CK estimation used at the MCNN was the continuous flow version of Hughes's method (Hughes, 1962; Siegel and Cohen, 1966), which is based on the colorimetric determination of the creatine liberated from creatine phosphate at $37^{\circ} \mathrm{C}$. This method has been in use for nearly 20 years in muscular dystrophy laboratories, and was selected because its greatest precision is at the levels intermediate between those usual for controls and those for carriers of X-linked muscular dystrophy, and because it is suitable for large batches. The method used at the QEMC was the Boehringer CK 'activated' U-V method for automated analysis, employing the Vitatron AKES at $30^{\circ} \mathrm{C}$. This method measures spectrophotometrically the production of NADPH, which is ultimately a measure of the amount of ATP formed when CK splits creatine phosphate in the presence of ADP (Table 1). This method is more specific than Hughes's method, but it is essential that serum freshly separated from red cells is used, since ATP and glucose-6-phosphate

Table 1 Summary of CK metabolism to illustrate estimation procedures

\begin{tabular}{|c|c|c|}
\hline & CK & \\
\hline $\mathbf{C P}+\mathbf{A D P}$ & $\overline{\mathrm{HK}}$ & $\mathbf{C}+\mathbf{A T P}$ \\
\hline $\mathbf{A T P}+\mathbf{G}$ & $\overline{\text { G6PD }}$ & G-6-P + ADP \\
\hline G-6-P + NADP + & 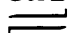 & Glu-6-P + NADPH $+\mathbf{H}^{+}$ \\
\hline
\end{tabular}

CP, creatine phosphate; ADP, adenosine diphosphate; $C K$, creatine kinase; C, creatine; ATP, adenosine triphosphate; G, glucose; HK, hexokinase; G-6-P, glucose-6-phosphate; NADP ${ }^{+}$, nicotinamide adenine dinucleotide phosphate; G6PD, glucose-6-phosphate dehydrogenase; Glu-6-P, gluconate-6-phosphate; NADPH, reduced NADP+. present in the red cells may leak out and produce falsely high results. The method is faster than the $\overrightarrow{\mathrm{D}}$ continuous flow procedure outlined above and is most precise for very high values.

Since the distribution of CK levels is not sym-o metrical about the mean, we have, like most othero workers, used the logarithms of values for our $\frac{\overline{\bar{c}}}{\overline{3}}$ graphical display and the calculation of the means, $\mathbb{\Omega}$ which are therefore geometrical means. The 'twoo standard deviations above the mean' is based on the ${ }^{\text {s }}$ logarithms of the values, on the assumption that they? are normal. In fact, there were occasional erratic $\vec{\overrightarrow{ }}$ high values which are outside the likely Gaussian approximation. These were not excluded from the calculations. Attempts to improve normality by other transformations produced limited improve- $\vec{\sigma}$ ments in fit at a disproportionate cost in complexity. $\stackrel{?}{?}$

\section{Results}

The schoolgirls were aged 12 to 16 , the nurses 20 to $\vec{D}$ 40 (with a mean of 24 years), the pregnant women? 17 to 41 , and the blood donors, who were assumed $\vec{\oplus}$ to be postmenopausal, were aged 55 years or over. Within the separate groups, there was no evidence. of regression of $\mathrm{CK}$ level with age except in the schoolgirls, where a small negative regression could be fully accounted for by the menarche.

The results of CK estimations are given in Table $2 \%$ and presented graphically in Fig. 1 and 2. The highest $\stackrel{\odot}{\circ}$ levels were found in the premenarchal schoolgirls, $\overrightarrow{\vec{A}}$ then the postmenarchal schoolgirls, then the nurses, 3 and then the pregnant women, whose levels were so much lower that their upper limit of 2 SD was below the mean for the schoolgirls. The levels in the postmenopausal women increased to about that of the⿳亠丷厂 postmenarchal girls.

Of the schoolgirls, 38 (aged 12 to 16 , with a mean age of $13 \cdot 3$ years) had not yet begun to menstruate.

Table 2 CK levels in 5 groups of females

\begin{tabular}{|c|c|c|c|c|c|}
\hline & $\begin{array}{l}\text { Teenage girls } \\
\text { Premenarchal }\end{array}$ & Postmenarchal & $\begin{array}{l}\text { Nurses } \\
(20-40 y)\end{array}$ & $\begin{array}{l}\text { Pregnant } \\
\text { women }\end{array}$ & $\begin{array}{l}\text { Women aged } \\
\text { over } 55\end{array}$ \\
\hline \multicolumn{6}{|l|}{ Results from $M C N N$} \\
\hline No & 38 & 110 & 133 & 124 & 37 \\
\hline Mean of data (logs) & $1 \cdot 740$ & $1 \cdot 634$ & $1 \cdot 520$ & $1 \cdot 396$ & $1 \cdot 644$ \\
\hline SD of data (logs) & $0 \cdot 156$ & $0 \cdot 170$ & $0 \cdot 175$ & $0 \cdot 152$ & $0 \cdot 129$ \\
\hline Antilog of mean (IU/1) & $55 \cdot 5$ & $43 \cdot 0$ & $33 \cdot 1$ & $24 \cdot 9$ & 44.0 \\
\hline $2 \mathrm{SD}$ range $(\mathrm{IU} / 1)$ & $26 \cdot 8-101 \cdot 2$ & $19 \cdot 7-94 \cdot 2$ & $14 \cdot 8-74 \cdot 1$ & $12 \cdot 4-50 \cdot 1$ & $24 \cdot 3-79 \cdot 6$ \\
\hline Ratio of (mean $+2 \mathrm{SD}$ ) to mean & $1 \cdot 8$ & $2 \cdot 2$ & $2 \cdot 2$ & $2 \cdot 0$ & $1 \cdot 8$ \\
\hline $\begin{array}{l}\text { No of results over } 75 \mathrm{IU} / 1 \\
\text { Results from } Q E M C\end{array}$ & $6(16 \%)$ & $9(8 \%)$ & $1(1 \%)$ & $1(1 \%)$ & $1(3 \%)$ \\
\hline No & 38 & 109 & 126 & 113 & 37 \\
\hline Mean of data (logs) & 1.672 & $1 \cdot 554$ & $1 \cdot 377$ & $1 \cdot 215$ & $1 \cdot 508$ \\
\hline SD of data (logs) & $0 \cdot 187$ & 0.196 & 0.252 & 0.201 & $0 \cdot 187$ \\
\hline Antilog of mean (IU/1) & $47 \cdot 0$ & $35 \cdot 8$ & $23 \cdot 8$ & $16 \cdot 4$ & $32 \cdot 2$ \\
\hline $2 \mathrm{SD}$ range $(\mathrm{IU} / \mathrm{l})$ & $19 \cdot 9-111 \cdot 2$ & $14 \cdot 5-88 \cdot 3$ & $7 \cdot 5-76 \cdot 0$ & $6 \cdot 5-41 \cdot 4$ & $13 \cdot 6-76 \cdot 2$ \\
\hline Ratio of (mean +2 SD) to mean & $2 \cdot 4$ & $2 \cdot 5$ & $3 \cdot 2$ & $2 \cdot 5$ & $2 \cdot 4$ \\
\hline No of results over $75 \mathrm{IU} / 1$ & $5(13 \%)$ & $6(6 \%)$ & $3(3 \%)$ & $1(1 \%)$ & $1(3 \%)$ \\
\hline
\end{tabular}




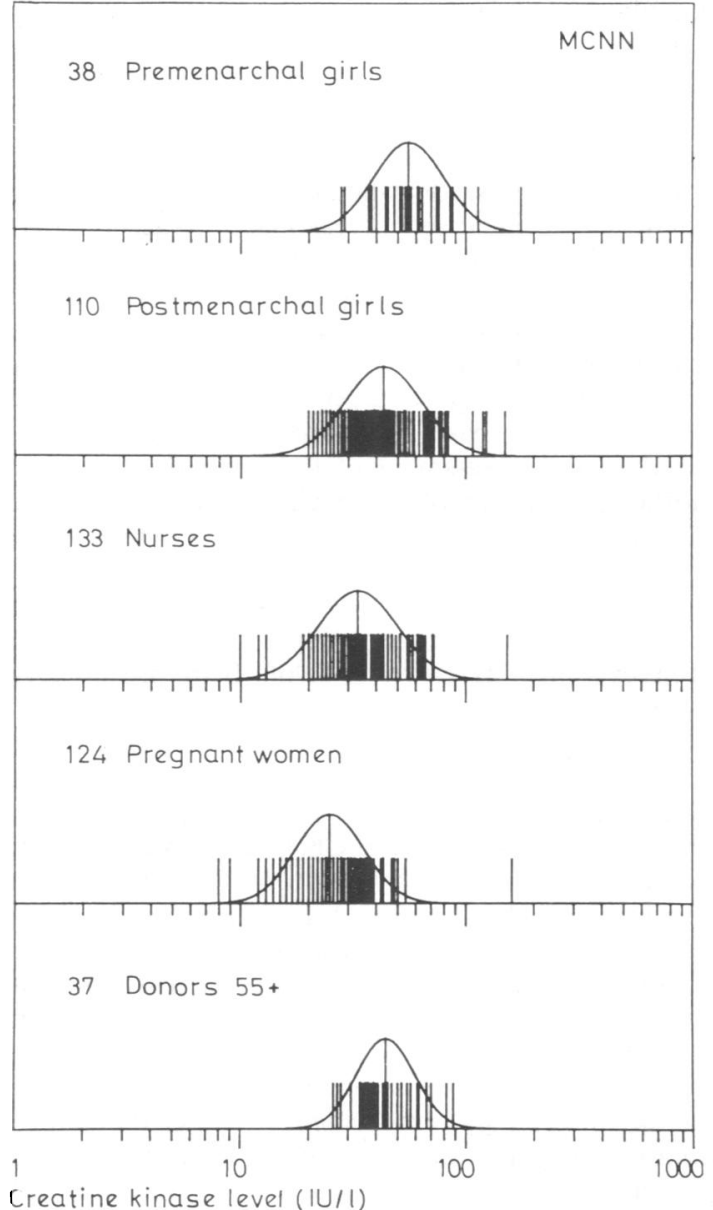

Fig. 1 Distributions of the MCNN CK levels of (from top downwards) premenarchal girls, postmenarchal girls, mature women, pregnant women, and postmenopausal women.

Their mean CK levels were more than $1 \frac{1}{2}$ times the means of the nurses, and more than twice the means of the pregnant women (Table 2). The 110 schoolgirls who had started to menstruate had CK levels that were intermediate between those of the premenarchal girls and the nurses. The 21 girls who were menstruating on the day their blood was taken had CK levels that were distributed fairly randomly among the postmenarchal group, with a mean of $46.6 \mathrm{IU} / 1$ compared to $39.5 \mathrm{IU} / \mathrm{l}$ in the others.

The 124 pregnant women, whose gestations ranged from 6 to 16 weeks, had mean CK levels of 24.9 and 16.4 IU/l. There was no regression of CK level on gestation within their dates. In two women we studied CK levels before and after conception. In

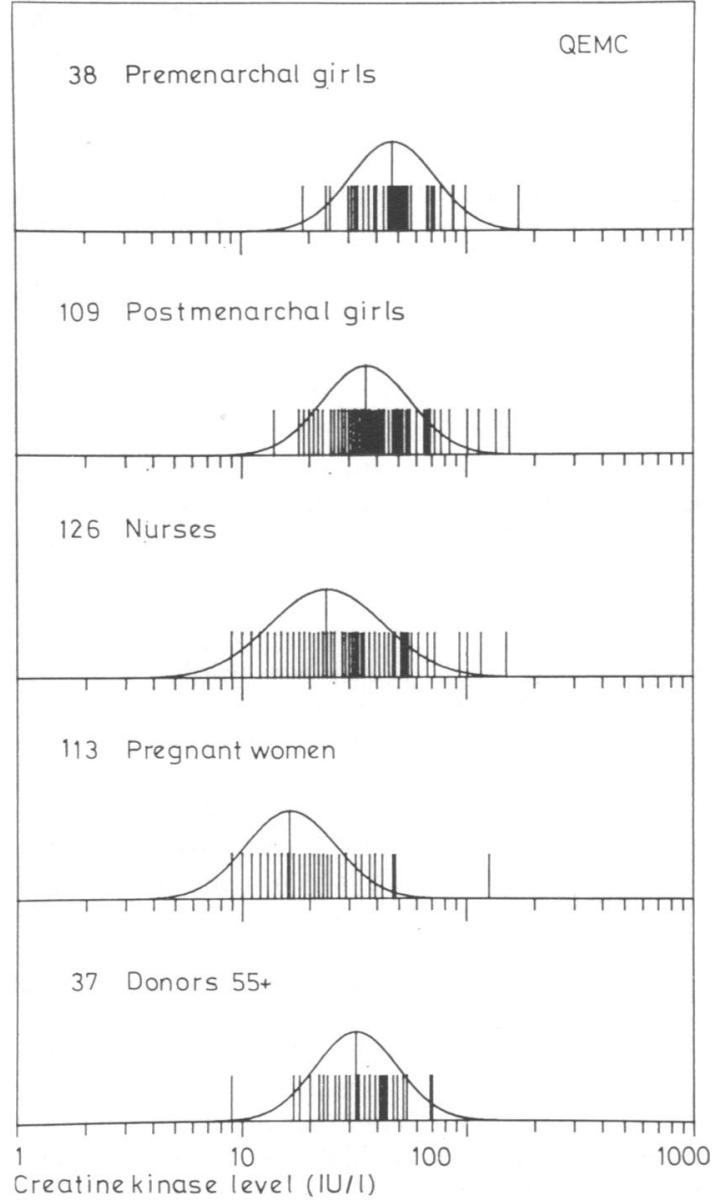

Fig. 2 Distributions of the QEMC CK levels of (from top downwards) premenarchal girls, postmenarchal girls, mature women, pregnant women, and postmenopausal women.

one, the CK level had fallen from previous levels of 36,35 , and $36 \mathrm{IU} / 1$ to $24 \mathrm{IU} / 1$ on the first day of her first missed period, and continued to be low throughout her pregnancy $(14,22,16,23,23 \mathrm{IU} / \mathrm{l})$. In the other woman, there was a smaller fall from prepregnancy levels of $34,24,23$, and $23 \mathrm{UI} / 1$ to pregnancy levels of 20 and $19 \mathrm{IU} / 1$ before she had a spontaneous abortion at 10 weeks.

\section{Discussion}

The diagnosis of potential carriers of Duchenne muscular dystrophy cannot yet be made with certainty, and the level of creatine kinase in the serum is the most informative test on the likelihood 
of an individual being a carrier. The inference, after allowance for the likelihood based on relationship, is based on a comparison with normal levels, which are often assumed to be largely uninfluenced by age. However, we have found far higher levels of CK in healthy young girls than in mature women, substantially lower levels of CK in pregnant women (also shown by King et al., 1972), and higher values again after the menopause (also observed by Sweetin and Thomson, 1973).

Several groups of workers (Thompson et al., 1967; Perry and Fraser, 1973; Moser and Vogt, 1974; Zatz et al., 1976) have suggested that teenage carriers of Duchenne muscular dystrophy have higher levels of CK than adult carriers. However, the evidence for this has been indirect, since a carrier can rarely, if ever, be recognised when in her teens as she would have had to have had an affected son. Thompson et al. (1967) and Zatz et al. (1976) observed that while about two-thirds of known carriers for Duchenne muscular dystrophy had raised CK levels, the number of sisters of patients who had raised CK levels was similar to the number expected to be carriers on the basis of their mother's status. Perry and Fraser (1973) and Zatz et al. (1976) have reported families in which a mother has had normal CK levels and a daughter high levels. Indeed, Zatz et al. (1975) have suggested that such mothers should be considered to be carriers on the basis of their daughter's results. Moser and Vogt (1974) followed CK levels in 19 definite and possible carriers for Duchenne muscular dystrophy over a 13-year period. They found that during this time the number of females with high CK levels had fallen from 14 in 1961 (5 definite and 9 possible carriers) to 6 in 1974 ( 3 definite and 3 possible carriers). These changes could not be attributed to variation in laboratory technique, but were explained by changes of CK levels with age. Subsequently, Moser (1977, 1978, personal communication) examined carrier detection rates using $\mathrm{CK}$ levels in 116 female relatives, and compared the results to the numbers of carriers expected from detailed pedigree analysis. He found that while carrier detection was $65 \%$ of that expected after the age of 20 (in accordance with other workers), it was $91 \%$ under the age of 20 . $\mathrm{He}$ therefore advocates estimating CK levels on female relatives when they are young. However, such analysis gives no information on whether those classified as carriers are correctly classified, but only that any false-positives are balanced by similar numbers of false-negatives.

If young girls are going to be tested and advice given, it is essential that their CK levels are compared with those of a similar population. The higher CK levels reported here among teenage girls raises the possibility that the higher detection rate in young girls may partly result from the inclusion of false $\frac{\mathbb{T}}{?}$ positives. It cannot be known whether the $\mathrm{CK}$ : levels of teenage carriers for Duchenne musculaf? dystrophy are raised to the same extent as those of normal teenagers, or whether to a much greate extent. However, it seems reasonable to assume thaf they will be raised and that the level of mean plus $2 \mathrm{SD}$ is a satisfactory point at which to divide possible carriers into probable carriers or unlikely carriers:In a study of Duchenne muscular dystrophy (Bundey et al., 1978), there were 52 possible carriers under the age of 20. On the basis of individual pedigree analysis together with assessment of the CK values in theip mothers, 17 to 18 of these girls were likely to be carriers. Of these, 16 had CK levels which were above the 2 SD range for their appropriate controls $\stackrel{n}{!}$ If the levels in those 52 girls had been compared to those of an adult female population, 23 would haves been classified as carriers, 7 of them presumably. incorrectly.

The lowering of CK levels in early pregnancy may? be analogous to the effect of the menarche, but is difficult to explain. Very few proteins are reduced in pregnancy. The lowering of CK levels in pregnancy in ${ }^{\circ}$ carriers was observed by Blyth and Hughes (1971) and Emery and King (1971), and King et al. (1972) subsequently described a lowering of CK levels in pregnant normal women. The present study not only shows a substantial reduction of CK levels in early pregnancy, but, on the findings in one woman, $\vec{乛}$ suggests that this reduction may have occurred by the time pregnancy is suspected. It will be difficult tor obtain adequate numbers of pregnant obligateo carriers to define their range of CK levels at al accurately.

These effects of puberty, pregnancy, and themenopause on CK levels in healthy women raise the possibility that other hormonal influences, such as menstruation and the contraceptive pill, may alter CK levels. However, previous workers have notedo no effect of menstruation (Pearce et al., 1964; Wilson et al., 1965; Perry and Fraser, 1973), thoughe Sweetin and Thomson (1973) observed higher CK levels in the second half of the menstrual cycles Similarly, previous workers have found no effect off the contraceptive pill on CK levels (Perry and Fraser, N 1973; Simpson et al., 1974). In the present study, an appreciable proportion of the nurses was likely to be using oral contraceptives, but we have no infor-c mation on this.

The numbers of results in each group which exceeded two SD (Table 2) were greater than theo proportion defined by a Gaussian distribution. In noه group would it be possible to infer the upper centile distribution from the Gaussian approximation. 
However, there might have been fewer outlying results had it been possible to make several estimations on the same individual, as is recommended when testing possible carriers (Wilson et al., 1965).

We are grateful to Dr J. Insley for access to blood samples from nurses, to $\mathrm{Mr} \mathrm{H}$. Roberts and $\mathrm{Mr} \mathrm{H}$. $O$. Nicholson for access to blood samples from their pregnant patients, and to Dr G. W. G. Bird and Mrs Pauline Mackintosh for the provision of samples from the small proportion of blood donors who were over 55. We are also grateful to Miss Evans, Mrs Rutter, Dr Isobel Cant, and the pupils of King Edward's High School for girls, for their help and gifts of blood. We thank Dr Susan Hickey for performing the CK estimations at MCNN, Dr A. M. Bold for his advice over methods for estimation of CK levels, and Dr G. W. Pearce for his help and encouragement. The work was supported by The Muscular Dystrophy Group of Great Britain.

\section{References}

Blyth, H., and Hughes, B. P. (1971). Pregnancy and serumCPK levels in potential carriers of 'severe' $X$-linked muscular dystrophy. (Letter.) Lancet, 1, 855-856.

Bundey, S., Edwards, J. H., and Insley, J. I. (1979). A genetic study of Duchenne muscular dystrophy in the West Midlands. (In preparation.)

Emery, A. E. H., and King, B. (1971). Pregnancy and serum creatine kinase levels in potential carriers of Duchenne X-linked muscular dystrophy. (Letter.) Lancet, 1, 1013.

Hughes, B. P. (1962). A method for the estimation of serum creatine kinase and its use in comparing creatine kinase and aldolase activity in normal and pathological sera. Clinica Chimica Acta, 7, 597-603.

King, B., Spikesman, A., and Emery, A. E. H. (1972). The effect of pregnancy on serum levels of creatine kinase. Clinica Chimica Acta, 36, 257-259.
Moser, H. (1977). Heterozygotenerfassung und genetische Beratung bei der progressiven Muskeldystrophie Duchenne. Schweizerische Rundschau für Medizin (Praxis), 66, Nr 27, 814-822.

Moser, H., and Vogt, J. (1974). Follow-up study of serumcreatine-kinase in carriers of Duchenne muscular dystrophy. (Letter.) Lancet, 2, 661-662.

Pearce, J. M. S., Pennington, R. J., and Walton, J. N. (1964). Serum enzyme studies in muscle disease. Part I. Variations in serum creatine kinase activity in normal individuals. Journal of Neurology, Neurosurgery and Psychiatry, 27, 1-4.

Perry, T. B., and Fraser, F. C. (1973). Variability of serum creatine phosphokinase activity in normal women and carriers of the gene for Duchenne muscular dystrophy. Neurology, 23, 1316-1323.

Siegel, A. L., and Cohen, P. S. (1966). An automated determination of serum creatine phosphokinase. Clinical Chemistry, 12, 532.

Simpson, J., Zellweger, H., Burmeister, L. F., Christee, R., and Nielsen, M. K. (1974). Effect of oral contraceptive pills on the level of creatine phosphokinase with regard to carrier detection in Duchenne muscular dystrophy. Clinica Chimica Acta, 52, 219-223.

Sweetin, J. C., and Thomson, W. H. S. (1973). Revised normal ranges for six serum enzymes. Clinica Chimica Acta, 48, 49-63.

Thompson, M. W., Murphy, E. G., and McAlpine, P. J. (1967). An assessment of the creatine kinase test in the detection of carriers of Duchenne muscular dystrophy. Journal of Pediatrics, 71, 82-93.

Wilson, K. M., Evans, K. A., and Carter, C. O. (1965). Creatine kinase levels in women who carry genes for three types of muscular dystrophy. British Medical Journal, 1, 750-753.

Zatz, M., Froto-Pessoa, O., Levy, J. A., and Peres, C. A. (1976). Creatine-phosphokinase (CPK) activity in relatives of patients with X-linked muscular dystrophies: a Brazilian study. Journal de Génétique Humaine, 24, 153-168.

Zatz, M., Froto-Pessoa, O., and Peres, C. A. (1975). Use of normal daughters' CPK levels in the estimation of heterozygosity risks in X-linked muscular dystrophies. Human Heredity, 25, 354-359.

Requests for reprints to Dr Sarah Bundey, Department of Clinical Genetics, Birmingham Maternity Hospital, Birmingham B15 2TG. 